\title{
Assessment of Immunoreactivity against Therapeutic Options Employing the Leukocyte Adherence Inhibition Test as a Tool for Precision Medicine
}

\author{
Celso E. Olivier, Daiana G. Pinto, Regiane P. S. Lima, Mariana D. Silva, Raquel A. P. G. Santos, \\ Ana P. M. Teixeira, and Patricia U. Simioni
}

\section{ABSTRACT}

Background: The Precision Medicine's approach employs the endotype concept as a central feature to personalize medical treatment. Individual immunoreactivity, alongside characteristics such as genetics, environment, and diet, is one of the factors that differentiates the therapeutic-driven endotypes.

Objective: To evaluate the opportunity of the Leukocyte Adherence Inhibition test to differentiate the immunoreactivity between two similar therapeutic agents employed on Allergen Immunotherapy.

Methods: Side by side Leukocyte Adherence Inhibitions tests were performed with ovalbumin and carbamylated ovalbumin on a population of 33 selfreported egg-allergic individuals.

Results: The results showed two endotypes inside the immune response of the studied groups: The first endotype was defined by the 16 individuals that presented a significant decrease in ovalbumin's immunoreactivity after carbamylation (mean of differences $=35 \% ; p=0.002$ ). The second endotype was defined by 17 individuals that presented a significant increase in ovalbumin's immunoreactivity after carbamylation (mean of differences $=$ $32 \% ; \mathbf{p}=\mathbf{0 . 0 0 1})$.

Conclusion: The Leukocyte Adherence Inhibition test was able to differentiate two distinct immunoreactivity patterns when comparing two similar therapeutic agents suggesting, as proof of concept, a potential role to be employed as a Precision Medicine tool.

Keywords: Allergoids, Leukocyte Adherence Inhibition test, Hypersensitivity, Precision Medicine.

\section{Abbreviations:}

LA: Leukocyte Adherence

LAR: Leukocyte Adherence Ratio

LAI: Leukocyte Adherence Inhibition

OVA: ovalbumin

cOVA: carbamylated ovalbumin

pOVA: phosphorylated OVA
Published Online: June 19, 2021

ISSN: $2736-5476$

DOI: $10.24018 /$ ejclinicmed.2021.2.3.81

Celso Eduardo Olivier*

Instituto Alergoimuno de Americana (Americana's Alergoimuno Institute), Rua Cuba, 836, Americana, São Paulo, Brazil.

(e-mail: celso@alergoimuno.med.br)

\section{Daiana Guedes Pinto}

Instituto Alergoimuno de Americana (Americana's Alergoimuno Institute), Rua Cuba, 836, Americana, São Paulo, Brazil.

(e-mail: daianaguedes85@gmail.com)

Regiane Patussi dos Santos Lima Instituto Alergoimuno de Americana (Americana's Alergoimuno Institute), Rua Cuba, 836, Americana, São Paulo, Brazil.

(e-mail: regianepatussi@ ${ }^{\circledR}$ gmail.com)

Mariana Dias da Silva

Instituto Alergoimuno de Americana (Americana's Alergoimuno Institute), Rua Cuba, 836, Americana, São Paulo, Brazil.

(e-mail: mari20-pira@ hotmail.com)

Raquel Acácia Pereira Gonçalves dos Santos

Instituto Alergoimuno de Americana (Americana's Alergoimuno Institute), Rua Cuba, 836, Americana, São Paulo, Brazil.

(e-mail: raquel.cuidados ${ }^{@}$ gmail.com)

Ana Paula Monezzi Teixeira

Faculdade de Americana

(Americana's Faculty)

Avenida Joaquim Bôer, 733,

Americana, São Paulo, Brazil.

(e-mail: monezzi88@gmail.com)

Patricia Ucelli Simioni

Faculdade de Americana

(Americana's Faculty)

Avenida Joaquim Bôer,

Americana, São Paulo, Brazil.

(e-mail: psimioni@gmail.com)

*Corresponding Author 


\section{INTRODUCTION}

Among the main causes of allergic symptoms that deserve a Precision Medicine approach are food allergies [1][5]. The Precision Medicine Initiative is a worldwide effort created to provide personalized care to patients based on the concept of the existence of different endotypes inside the larger phenotype groups as defined by modern Medicine [6][8]. The Precision Medicine approach also embraces the "complex endotype" concept, consisting of several subendotypes, instead of a single simplified endotype molecular mechanism [9]. Precision Medicine is mainly focused on therapeutic-driven endotypes, i.e. particular phenotypesubgroups that will better respond to a given therapy, instead of another [10]. The main concern is to increase efficacy and decrease collateral effects in the assumption that the peculiarities of each patient will produce diverse beneficial as well different collateral responses to the same therapeutic, as observed inside the whole population [11]. The development of Precision Medicine is based on the development of diagnostic assays to predict the specific response of each patient to a potential therapy, before the prescription of the treatment [12]. This concern, in the field of Allergology, has already originated the conception of more immunogenic and less allergenic alternatives to allergen-specific immunotherapy: the elaboration of modified allergens, the allergoids [13]. The use of allergoids for desensitization of allergic diseases has been reported since 1938 when Sledge et al. treated their hay fever patients sensitive to grass and ragweed with alum-precipitated pollen extracts, asserting that this modification provided better results and a significant reduction of "constitutional reactions" when compared with the natural extracts [14]. However, despite the alumprecipitated extracts could act better for some patients, some individuals presented allergic symptoms to the alum itself, characterizing a novel endotype among the patients belonging to this allergic phenotype [15]. Since then, dozens of techniques and adjuvants were described to decrease allergenicity and increase the immunogenicity of allergoids to provide a safer, more comfortable, personalized, and effective desensitization to allergic patients. One of the techniques employed to produce allergoids is protein carbamylation [16]. Protein carbamylation is a phenomenon that occurs naturally inside urea producers' organisms. The electrophilic species in equilibrium with urea: cyanate and isocyanate can react with lysine residues of proteins in an irreversible posttranslational modification, producing a carbamoyl group [17]. This spontaneous carbamylation occurring into physiologic systems (mainly in individuals with the uremic syndrome) may be assayed by colorimetric methods and is also considered a signal of molecular aging, related to degenerative disorders such as atherosclerosis and rheumatic inflammation [18], [19]. Minor changes in tridimensional conformation, such as the produced by carbamylation, can alter immunoreactivity, which depends on the antigen's conformational epitope [20]. This modification done in vitro can impair the binding of a reaginic antibody to the natural antigen, converting the desensitization's allergen into an allergoid [21]. Theoretically, this may not necessarily alter its tolerogenic capacity, which depends on the linear epitopes produced by Dendritic Cell's intracellular digestion that are presented to the naive T Cells into the MHC class II context [22].

As a proof of concept, we compared the immunoreactivity of self-reported egg-allergic individuals against a natural allergen: the ovalbumin ( $\mathrm{Gal} \mathrm{d} \mathrm{2)}$ ) and its corresponding carbamylated allergoid. Ovalbumin is the main egg white hen's protein with an approximate molecular weight of 43 $\mathrm{kDa}$ and consists of 385 amino acids single chain, 19 of which are lysine residues [23]. Meta-analyses comparing diverse diagnostic criteria (self-reported, skin tests, specific-IgE, and double-blind placebo-controlled provocation tests (DBPCPT) estimated that hypersensitivity to the egg is among the three most common causes of food allergic reactions [24]. The prevalence of food allergic reactions is relatively greater when the self-reported method is employed, compared with the objective diagnostic methods, but interestingly, the prevalence's ranking among the eliciting allergens is consistently maintained when comparing the objective and the self-reported criteria. This is understandable when we consider that allergy may be mediated by immune mechanisms not dependent on $\operatorname{IgE}$ and that food hypersensitivity reactions may also be dependent on thresholds, drugs, and physiologic stimuli, not always employed by in vivo provocation's tests [25]-[28]. Ovalbumin is not the most allergenic protein of hen's egg (the most allergenic is ovomucoid), but it is the most abundant and accessible protein in albumen [29]. Additionally, albumins are an interesting model to study immunoreactivity because they are produced by the human liver (human serum albumin), are present in significant amounts in human blood, and can be found in several edible animals and plants with a high degree of conservative evolution, resulting in both the possibilities of natural immunotolerance or cross-reactive hypersensitivity [30], [31]. Additionally, ovalbumin is also a very well-studied experimental inducer of tolerogenic Dendritic Cells [32]-[34]. One of the main functions of the albumins are the internal transport of ligands due to their conformational flexibility, another factor to alter their allergenicity [35]. There are three subclasses in the purified ovalbumin, according to their phosphate group content (two, one, or none) [36]. Four interchangeable secondary structures are found in an ovalbumin sample: alpha-helix, beta-sheet, random coil, and beta-turns. The heating stimulates denaturation, decreasing the alpha-helices and increasing the aggregational beta-sheets (beta-aggregation) [37]. These characteristics predict a broad specter of possibilities for immune reactions and sensitization mechanisms. To compare the general immunoreactivity against this complex allergen and its correspondent carbamylated allergoid, we used the Leukocyte Adherence Inhibition Test (LAI test) employing heparinized plasma of human patients with self-reported egg allergy. Leukocytes are naturally programmed to adhere to glass in physiologic conditions, which can be easily observed with an optical microscope and a glass surface hemocytometer chamber [38]. When functionally activated, they lose this capability, which allowed Halliday to design an antigen-specific ex vivo challenge named Leukocyte Adherence Inhibition test (LAI test) [39]. Challenged by specific antigens, leukocytes release paracrine soluble factors that interfere with glass adherence of nearby leukocytes, a phenomenon that can be quantified with a concomitant assay done with unchallenged plasma. Several immune mechanisms can produce this phenomenon, which seems to be just the final indicator of the antigen-specific leukocyte 
activation or, in other words, the immunoreactivity [40]-[43].

\section{METHODS}

\section{A. Subjects}

After receiving Institutional Review Board approval, from the Instituto Alergoimuno de Americana (Brazil), 33 consecutive outpatients complaining of self-reported challenge-proofed clinical symptoms compatible with hen's egg allergy, were invited, with informed consent formularies, to voluntarily provide blood samples to perform ex vivo challenge tests, according to the principles of Helsinki and the International Committee of Medical Journals Editors requirements of privacy. All patients had non-detectable specific IgE to ovalbumin and inconclusive skin tests (unreactive histamine controls) [44]. The study was purely descriptive and did not interfere with the patient's treatment or the assistant physician's diagnosis. All relevant and mandatory laboratory health and safety measures have complied within the complete course of the experiments.

\section{B. Carbamylation}

Ovalbumin was purchased as a powder from SigmaAldrich Brasil Ltda EPP (Cotia - SP - Brazil). The carbamylation was performed after dilution of ovalbumin in a borax buffer $(4 \mathrm{mg} / \mathrm{mL})$ followed by the addition of potassium cyanate $(0.5 \mathrm{M})$ and kept overnight at $40{ }^{\circ} \mathrm{C}$ [45], [46]. The final solution was submitted to $\mathrm{NaCl}(0.15 \mathrm{M})$ and EDTA (10g/L) buffer dialysis adjusted to $\mathrm{pH} 5.0$ for 24 hours to remove residual cyanate ions. Two blank ovalbumin solutions were prepared with (and without) potassium chloride $(0.5 \mathrm{M})$ instead of potassium cyanate. The three final solutions were adjusted to $\mathrm{pH} 7,5$ with $\mathrm{HCl}$ and to $1 \mathrm{mg} / \mathrm{mL}$ as quantified by Bradford methodology [47]. The phosphated ovalbumin (pOVA) was used only to control the electrophoretic running. The LAI tests were done parallelly with the purified ovalbumin (OVA) and the carbamylated ovalbumin (cOVA).

\section{Sodium Dodecyl Sulfate (SDS)-Polyacrylamide Electrophoresis Gell}

We compared, side by side, the purified, the phosphated, and the carbamylated ovalbumin utilizing a Coomassie ${ }^{\circledR}$ Blue stained $6 \%$ resolving sodium-dodecyl sulfate acrylamide $(6 \%)$ / bis-acrylamide (40\%) electrophoresis gel (SDSPAGE) performed with a Mini Protean Tetra Cell apparatus (Bio-Rad, CA, USA) [48]. Aliquots of $5 \mu \mathrm{L}$ of each extract were applied to each lane. A 10-180 KDa molecular mass Thermo Scientific prestained protein ladder (PageRuler ${ }^{\mathrm{TM}}$, Thermo Fisher, MA, USA) was used to identify approximate molecular weights. After electrophoresis, the gel was stained with Thermo Fisher Coomassie ${ }^{\circledR}$ Blue to identify the protein molecular weight distribution.

\section{Leucocyte Adherence Inhibition Test}

Plasma samples were collected in heparinized collection tubes. The ex vivo challenge tests were performed as described previously [49]. Each patient's fresh plasma was divided into three parts and used in two simultaneous and paralleled ex vivo challenging tests with purified ovalbumin (OVA) and the carbamylated ovalbumin (cOVA), both controlled by the third unchallenged plasma assay. The plasma with high leukocyte content (buffy coat) was collected from the heparinized tube after one hour of sedimentation at $37{ }^{\circ} \mathrm{C}$ and aliquots of $100 \mu \mathrm{L}$ were distributed into Eppendorf tubes kept under agitation for 30 minutes $\left(200 \mathrm{rpm}\right.$ at $37{ }^{\circ} \mathrm{C}$ ) with (or without, as used as control) antigen extract $(10 \mu \mathrm{L}$ of a solution with $1 \mathrm{mg} / \mathrm{mL}$ and $\mathrm{pH}$ 7.5). After incubation, the plasma was allocated into a standard Neubauer hemocytometer counting chamber with a plain, non-metallic glass surface and left to stand for 2 hours at $37^{\circ} \mathrm{C}$ in the humidified atmosphere of the covered water bath to allow leukocytes to adhere to the glass. Next, leukocytes were counted, the coverslip was removed, and the chamber was washed by immersion in a beaker with PBS at $37{ }^{\circ} \mathrm{C}$. A drop of PBS was added to the hemocytometer chamber and a clean coverslip was placed over it. The remaining cells were counted in the same squares as previously examined. The percentage of Leukocyte Adherence (LA) of each assay was estimated as: (the number of leukocytes observed on the hemocytometry chamber after washing divided by the number of leukocytes observed on the hemocytometry chamber before washing) and multiplied by $100(\%)$. The Leukocyte Adherence Ratio (LAR) was estimated based on the ratio between the LA from the antigen-specific challenged groups and the LA from the unchallenged control group: LAR = LA of the challenged sample divided by LA of unchallenged control sample; multiplied by $100(\%)$. To further calculate the Leukocyte Adherence Inhibition (LAI) the LAR was subtracted from $100(\%)$.

\section{E. Statistical Analyses}

Statistical analyses were performed using GraphPad Prism software (version 5.0; GraphPad Software, Inc., San Diego, CA, USA). The data were reported as arithmetic means with 95\% confidence intervals (CI) and standard deviations (SD). Differences in the means of matched samples were assessed by paired $t$-tests [50]. For all analyses, a p-value of less than 0.05 was considered significant. Two whiskers-and-box plot graphs were generated by the software.

\section{RESUlts}

The Coomassie ${ }^{\circledR}$ Blue-stained gel similarly showed two groups of proteins at the purified ovalbumin lane, the carbamylated ovalbumin lane, and the phosphated ovalbumin lane. The lighter group observed at approximately $43 \mathrm{kDa}$ corresponds to the monomeric alpha-helix. The heavier group with approximately $86 \mathrm{kDa}$ corresponds to the aggregated beta-sheet. The carbamylation interfered with the binding of the dye to the proteins but did not affect significantly their molecular weight (see Fig. 1).

When comparing the paired LAI responses inside the whole tested population, there was no significant difference by the $t$-test between OVA and cOVA immunoreactivity. However, we observed two distinct groups according to the results. The first group was defined by the 16 individuals that presented a significant decrease in ovalbumin's immunoreactivity (as assumed by the LAI) after carbamylation (mean of differences $=35 \% ; p=0.002$ ) as displayed in Fig. 2. The second group was defined by 17 
individuals that presented a significant increase in ovalbumin's immunoreactivity (as assumed by the LAI) after carbamylation (mean of differences $=32 \% ; p=0.001$ ) as displayed in Fig. 3. The main indicator that the carbamylation interfered randomly in the immunoreactivity to OVA was the fact that the previously paired challenge tests were considered "not paired" by the $t$-tests after carbamylation.

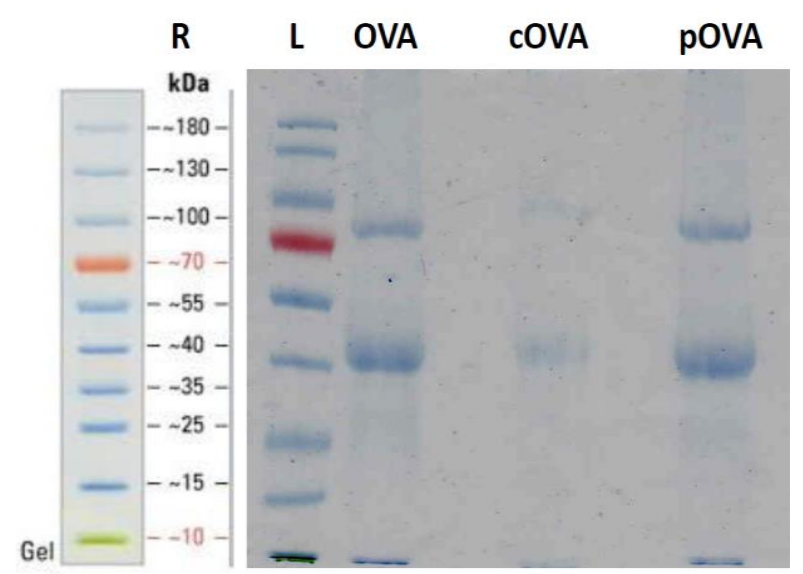

Fig. 1. Coomassie ${ }^{\circledR}$ Blue stained $6 \%$ resolving sodium-dodecyl sulfate (SDS)-polyacrylamide electrophoresis gel. R: Ruler; L: Ladder; OVA: ovalbumin; cOVA: carbamylated ovalbumin; pOVA: phosphorylated OVA.

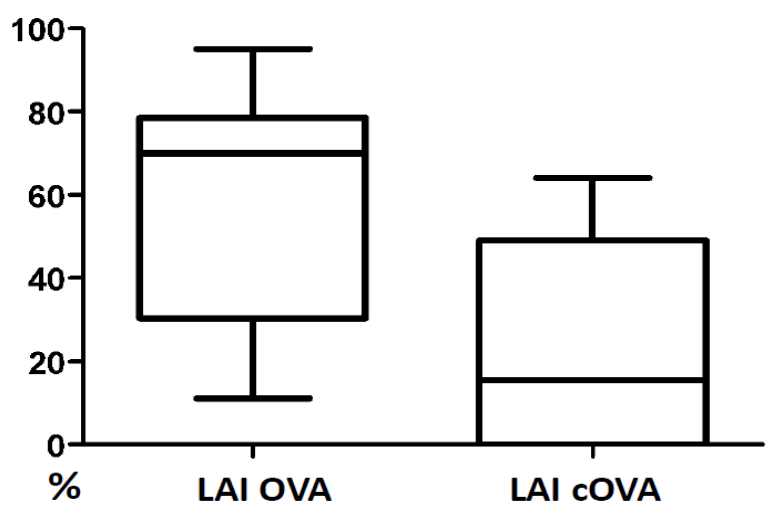

Fig. 2. Whiskers-and-box plot graph generated by GraphPad Prism software describing the paired $t$-test of the 16 individuals that presented a

decrease on ovalbumin's immunoreactivity after carbamylation as monitored by Leukocyte Adherence Inhibition Test (mean of differences = $35 \% ; \mathrm{p}=0.002)$.

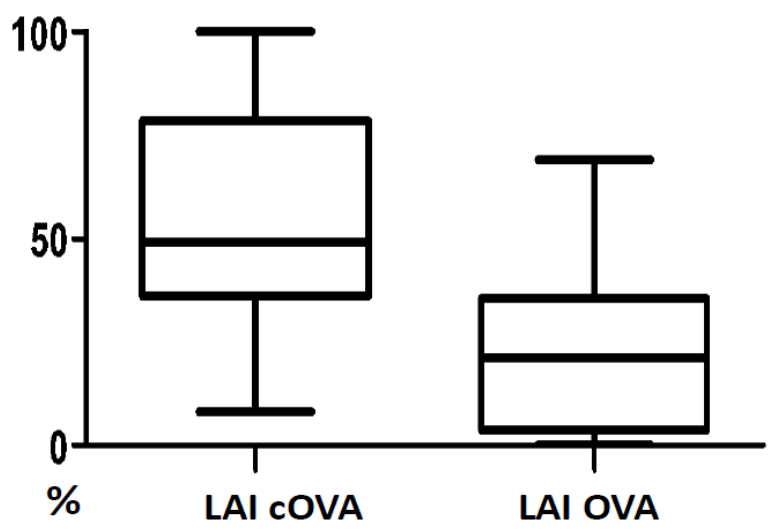

Fig. 3. Whiskers-and-box plot graph generated by GraphPad Prism software describing the paired $t$-test of the 17 individuals that presented an increase on ovalbumin's immunoreactivity after carbamylation as monitored by Leukocyte Adherence Inhibition Test (mean of differences = $32 \% ; \mathrm{p}=0.001)$

\section{DISCUSSION}

The design and the production of less allergenic food is a great concern not only for nutritional purposes but also for therapeutic interventions on food allergic people, mainly in this era characterized by the production of chemically, enzymatically, and/or genetically modified foods [51]. Usually, the concept of immunoreactivity employed by most food researchers with a nutritional background is exploited in its deleterious sense, referring to a reaginic immune reaction, usually mediated by IgE or IgG antibodies, associated with diseases, hypersensitivity or, at least, adverse reactions that can produce undesirable symptoms associated with the ingestion or even mere contact with specific food proteins [52]. But an immunologist must remember that the first and desirable immune reaction to food is immunotolerance. Tolerance to food is not the passive "absence" of immune reactions or unresponsiveness, but instead, is the resulting of an active and orchestrated interplay that establishes a chain of reconnaissance of specific nutritional proteins that the immune system identifies as beneficial to the body physiology. The major participants of this complex task are the tolerogenic Dendritic Cells, the regulatory $\mathrm{T}$ and $\mathrm{B}$ lymphocytes (Treg and Breg), the TGF- $\beta$, the IL-10, and the IgA [53]-[57]. The main determinant of the kind of immune response to be developed is the environment in which the allergens are collected by the Dendritic Cells before being presented to the naïve $\mathrm{T}$ Cells inside the lymph organs. According to the antigens' collecting environment, the Dendritic Cell expresses tolerogenic or costimulatory cytokines during the antigen presentation that drive the naïve $\mathrm{T}$ Cell to differentiate to a regulatory (tolerogenic) or a helper (inflammatory) phenotype [58]. When employing the LAI test to evaluate immunoreactivity we are not predicting the subsequent direction towards immunotolerance or hypersensitivity, but just the ability of the immune cells to recognize and respond to the specific antigen to which it is exposed. The inhibition of the leukocytes' glass adherence is just the final indicator of a non-specific release of cytokines. Therefore, this immunoassay is not designed to evaluate the utility of the LAI test to diagnosis allergy or to predict the patients' clinical response to the natural allergen or the carbamylated allergoid but to testify the first steps that drive the endotype differentiation. To predict the clinical response, it is necessary to employ information provided by others in vivo, in vitro, and ex vivo assays, such as the allergy cutaneous tests, the research of specific antibodies, the lymphocytes proliferation tests, or the basophils challenge tests, for instance. This experiment had the sole objective to explore the phenotype/endotype concept inside a Precision Medicine perspective. When evaluating the entire population, the statistical analysis found no significant difference in the immune response comparing the natural ovalbumin and the carbamylated allergoid. However, when the two different endotypes were defined, the statistical analyses revealed a significant difference characterizing the two trends of response. In conclusion, the objective of this work is to present a different perspective to evaluate the data, and instead of simply disqualify the mixed results, we propose to study more deeply the differences among the immune responses to extract additional information with the potential to improve and personalize the treatment of the therapeutic- 
driven endotypes.

\section{REFERENCES}

[1] F. Vega, C. Panizo, M. T. Dordal, M. L. González, E. Velázquez, A. Valero, et al. "Relationship between respiratory and food allergy and evaluation of preventive measures," Allergologia et Immunopathologia, vol. 44, no. 3, pp. 263-275, 2016.

[2] A. K. Sood, and A. M. Scurlock, "Food allergy oral immunotherapy," Journal of Food Allergy, vol. 2, no. 1, pp. 75-80, 2020.

[3] O. M. Schloss, "A Case of Allergy to Common Foods," Am J Dis Child, vol. III, no. 6, pp. 341-362, June 1, 1912, 1912.

[4] G. W. Canonica, C. Bachert, P. Hellings, D. Ryan, E. Valovirta, M. Wickman, O. De Beaumont, and J. Bousquet, "Allergen Immunotherapy (AIT): a prototype of Precision Medicine," World Allergy Organ J, vol. 8, no. 1, pp. 015-0079, 2015.

[5] F. S. Collins, and H. Varmus, "A New Initiative on Precision Medicine," New England Journal of Medicine, vol. 372, no. 9, pp. 793 795, 2015.

[6] P. L. Sankar, and L. S. Parker, "The Precision Medicine Initiative's All of Us Research Program: an agenda for research on its ethical, legal, and social issues," Genetics in Medicine, vol. 19, no. 7, pp. 743-750, 2017.

[7] C. Song, Y. Kong, L. Huang, H. Luo, and X. Zhu, "Big data-driven precision medicine: Starting the custom-made era of iatrology," Biomedicine \& Pharmacotherapy, vol. 129, pp. 110445, 2020.

[8] L. Chen, J. E. Manautou, T. P. Rasmussen, and X.-b. Zhong, "Development of precision medicine approaches based on interindividual variability of BCRP/ABCG2," Acta Pharmaceutica Sinica $B$, vol. 9, no. 4, pp. 659-674, 2019.

[9] I. Agache, and C. A. Akdis, "Endotypes of allergic diseases and asthma: An important step in building blocks for the future of precision medicine," Allergology International, vol. 65, no. 3, pp. 243-252, 2020

[10] A. Muraro, R. F. Lemanske, P. W. Hellings, C. A. Akdis, T. Bieber, T. B. Casale, et al. "Precision medicine in patients with allergic diseases: Airway diseases and atopic dermatitis; PRACTALL document of the European Academy of Allergy and Clinical Immunology and the American Academy of Allergy, Asthma \& Immunology," Journal of Allergy and Clinical Immunology, vol. 137, no. 5, pp. 1347-1358, 2016

[11] I. Miyagawa, and Y. Tanaka, "The approach to precision medicine for the treatment of psoriatic arthritis," Immunological Medicine, vol. 43 , no. 3, pp. 98-102, 2020.

[12] B. Shen, and J. Hwang, "The clinical utility of precision medicine: properly assessing the value of emerging diagnostic tests," Clin Pharmacol Ther, vol. 88, no. 6, pp. 754-6, Dec, 2010.

[13] C. E. Olivier, "The use of allergoids and adjuvants in Allergen Immunotherapy," Arch Asthma Allergy Immunol, vol. 1, pp. 40-60, 2017.

[14] R. F. Sledge, "Treatment of hay fever with alum-precipitated pollen extract," Journal of Allergy, vol. 9, no. 4, pp. 424, 2017/07/28, 1938.

[15] P. Y. Castelain, M. Castelain, D. Vervloet, L. Garbe, and B. Mallet, "Sensitization to aluminium by aluminium-precipitated dust and pollen extracts," Contact Dermatitis, vol. 19, no. 1, pp. 58-60, 1988.

[16] C. Lombardi, S. Gargioni, A. Melchiorre, A. Tiri, P. Falagiani, G. W. Canonica, and G. Passalacqua, "Safety of sublingual immunotherapy with monomeric allergoid in adults: multicenter post-marketing surveillance study," Allergy, vol. 56, no. 10, pp. 989-92, Oct, 2001.

[17] M. T. Velasquez, A. Ramezani, and D. S. Raj, "Urea and protein carbamylation in ESRD: surrogate markers or partners in crime?," Kidney Int, vol. 87, no. 6, pp. 1092-4, 2015.

[18] S. p. Jaisson, C. Pietrement, P. Gillery, and G. S. Makowski, "Chapter One - Protein Carbamylation: Chemistry, Pathophysiological Involvement, and Biomarkers," Advances in Clinical Chemistry, pp. 138: Elsevier, 2018.

[19] A. G. Basnakian, S. V. Shah, E. Ok, E. Altunel, E. O. Apostolov, and G. S. Makowski, "Carbamylated LDL," Advances in Clinical Chemistry, pp. 25-52: Elsevier, 2010.

[20] J. L. Sanchez-Trincado, M. Gomez-Perosanz, and P. A. Reche, "Fundamentals and Methods for T- and B-Cell Epitope Prediction," Journal of Immunology Research, vol. 2017, pp. $2680160,2017$.

[21] R. Mösges, B. Ritter, G. Kayoko, D. Passali, and S. Allekotte, "Carbamylated monomeric allergoids as a therapeutic option for sublingual immunotherapy of dust mite- and grass pollen-induced allergic rhinoconjunctivitis: a systematic review of published trials with a meta-analysis of treatment using Lais ${ }^{\circledR}$ tablets.," Acta Dermatovenerologica APA, vol. 19, no. 3, pp. 3-10, 2010.

[22] T. ten Broeke, R. Wubbolts, and W. Stoorvogel, "MHC class II antigen presentation by dendritic cells regulated through endosomal sorting,"
Cold Spring Harbor perspectives in biology, vol. 5, no. 12, pp. a016873-a016873, 2013.

[23] A. D. Nisbet, R. H. Saundry, A. J. G. Moir, L. A. Fothergill, and J. E. Fothergill, "The Complete Amino-Acid Sequence of Hen Ovalbumin," European Journal of Biochemistry, vol. 115, no. 2, pp. 335-345, 2021/02/04, 1981

[24] R. J. Rona, T. Keil, C. Summers, D. Gislason, L. Zuidmeer, E Sodergren, et al. "The prevalence of food allergy: A meta-analysis," Journal of Allergy and Clinical Immunology, vol. 120, no. 3, pp. 638646, 2021/02/09, 2007

[25] P. G. H. Gell, and R. R. A. Coombs, "Classification of Allergic Reactions Responsible for Clinical Hypersensitivity and Disease.," Clinical Aspects of Immunology, P. G. H. Gell and R. R. A. Coombs, eds., pp. 575-596, Oxford: Blackwell Scientific Publications, 1968.

[26] S. L. Taylor, S. M. Gendel, G. F. Houben, and E. Julien, "The Key Events Dose-Response Framework: a foundation for examining variability in elicitation thresholds for food allergens," Crit Rev Food Sci Nutr, vol. 49, no. 8, pp. 729-39, Sep, 2009.

[27] Olivier CE, Santos RAPG, Argentão DGP, S. MD, and L. RPS, "Fooddependent drug-induced angioedema: a case report," J Allergy Immunol, 2017 DOI: 10.15761/JAI.1000101, 2017.

[28] Y. Aihara, T. Kotoyori, Y. Takahashi, H. Osuna, S. Ohnuma, and Z. Ikezawa, "The necessity for dual food intake to provoke fooddependent exercise-induced anaphylaxis (FEIAn): a case report of FEIAn with simultaneous intake of wheat and umeboshi," J Allergy Clin Immunol, vol. 107, no. 6, pp. 1100-5, Jun, 2001.

[29] S. A. Hasan, R. D. Wells, and C. M. Davis, "Egg hypersensitivity in review," Allergy Asthma Proc, vol. 34, no. 1, pp. 26-32, 2013.

[30] M. Chruszcz, K. Mikolajczak, N. Mank, K. A. Majorek, P. J. Porebski, and W. Minor, "Serum albumins - unusual allergens; 2013," Biochimica et biophysica acta, vol. 1830, no. 12, pp. 5375-5381.

[31] F. J. Moreno, and A. Clemente, "2S Albumin Storage Proteins: What Makes them Food Allergens?," The open biochemistry journal, vol. 2 , pp. 16-28, 2008.

[32] R. Thomé, L. G. R. Fernandes, M. F. Mineiro, P. U. Simioni, P. P. Joazeiro, and W. M. d. S. C. Tamashiro, "Oral tolerance and OVAinduced tolerogenic dendritic cells reduce the severity of collagen/ovalbumin-induced arthritis in mice," Cellular Immunology, vol. 280, no. 1, pp. 113-123, 2012.

[33] P. U. Simioni, L. G. R. Fernandes, D. L. Gabriel, and W. M. S. C. Tamashiro, "Induction of Systemic Tolerance in Normal but not in Transgenic Mice Through Continuous Feeding of Ovalbumin," Scandinavian Journal of Immunology, vol. 60, no. 3, pp. 257-266, 2004.

[34] L. N. Paiatto, F. G. D. Silva, J. Bier, M. R. Brochetto-Braga, Á. T. Yamada, W. M. S. C. Tamashiro, and P. U. Simioni, "Oral Tolerance Induced by OVA Intake Ameliorates TNBS-Induced Colitis in Mice," PLoS ONE, vol. 12, no. 1, pp. e0170205, 2017.

[35] C.-H. Tang, and L. Shen, "Role of Conformational Flexibility in the Emulsifying Properties of Bovine Serum Albumin," Journal of Agricultural and Food Chemistry, vol. 61, no. 12, pp. 3097-3110, 2013.

[36] Y. Mine, "Recent advances in the understanding of egg white protein functionality," Trends in Food Science \& Technology, vol. 6, no. 7, pp. 225-232, 1995.

[37] S. Ngarize, H. Herman, A. Adams, and N. Howell, "Comparison of Changes in the Secondary Structure of Unheated, Heated, and HighPressure-Treated $\hat{\mathrm{I}}^{2}$-Lactoglobulin and Ovalbumin Proteins Using Fourier Transform Raman Spectroscopy and Self-Deconvolution," Journal of Agricultural and Food Chemistry, vol. 52, no. 21, pp. 64706477, 2004.

[38] D. M. P. Thomson, Assessment of immune status by the leukocyte adherence inhibition test, New York: Academic Press, 1982.

[39] W. J. Halliday, "Historical Background and Aspects of the Mechanism of Leukocyte Adherence Inhibition," Cancer Res, vol. 39, no. 2, pp. 558-563, February 1, 1979, 1979

[40] T. Appelboom, J. P. Famaey, R. Gortz, and J. Wybran, "Effect of levamisole on leukocyte adherence inhibition," Agents Actions, vol. 11, no. 6-7, pp. 604-5, Dec, 1981.

[41] A. Fink, H. Bibi, A. Eliraz, E. Tabachnik, and Z. Bentwich, "Leukotrienes (LTC4, LTD4) confer glass non-adherence on leukocytes of asthmatic individuals. Dependency on cyclooxygenase products and calcium ion," Immunol Lett, vol. 10, no. 6, pp. 319-23, 1985.

[42] A. Fink, R. Shahin, A. Eliraz, H. Bibi, H. Berkenstadt, S. Levin, and Z. Bentwich, "Interferon modulates the leukotriene C4-induced nonadherence properties of leukocytes: acquisition of an asthmatic phenotype," Immunol Lett, vol. 10, no. 3-4, pp. 159-63, 1985.

[43] K. Iwabuchi, and T. Yamashita, "Platelet-derived neutrophil adherence-inhibiting factor in humans," Blood, vol. 76, no. 11, pp. 2368-73, Dec 1, 1990. 
[44] C. E. Olivier, D. G. P. Argentão, R. A. P. G. Santos, M. D. Silva, R. P. S. Lima, and R. L. Zollner, "Skin scrape test: an inexpensive and painless skin test for recognition of immediate hypersensitivity in children and adults," The Open Allergy Journal, vol. 6, pp. 9-17, 2013.

[45] G. Mistrello, O. Brenna, D. Roncarolo, D. Zanoni, M. Gentili, and P. Falagiani, "Monomeric chemically modified allergens: Immunologic and physicochemical characterization," Allergy, vol. 51, no. 1, pp. 8 $15,1996$.

[46] A. D. E. Lauchlan, "Borax as a Standard Buffer Solution," Nature, vol. 154, no. 3914, pp. 577-577, 1944.

[47] M. M. Bradford, "A rapid and sensitive method for the quantitation of microgram quantities of protein utilizing the principle of protein-dye binding," Anal Biochem, vol. 72, pp. 248-54, 1976.

[48] K. Weber, J. R. Pringle, and M. Osborn, "Measurement of molecular weights by electrophoresis on SDS-acrylamide gel," Methods Enzymol, vol. $26 \mathrm{PtC}$, pp. 3-27, 1972.

[49] C. E. Olivier, R. P. S. Lima, D. G. Pinto, R. A. P. G. Santos, G. K. M. Silva, S. L. S. Lorena, et a., "In search of a tolerance-induction strategy for cow's milk allergies: significant reduction of beta-lactoglobulin allergenicity via transglutaminase/cysteine polymerization.," Clinics, vol. 67 , no. 10 , pp. 1171-1179, 2012.

[50] W. S. Gosset (Student), "The probable error of a mean," Biometrika, vol. 6, no. 1, pp. 1-25, 1908.

[51] J. Leszczynska, A. Lacka, and M. Bryszewska, "The use of transglutaminase in the reduction of immunoreactivity of wheat flour," Food and Agricultural Immunology, vol. 17, no. 2, pp. 105-113, 2006.

[52] A. F. Alkhateeb, "Foods Causing Highest IgG Immune Response in Saudi Arabia," Annual Research \& Review in Biology, pp. 115-127, 2020.

[53] A. M. Mowat, "Anatomical basis of tolerance and immunity to intestinal antigens," Nature Reviews Immunology, vol. 3, no. 4, pp. 331-341, 2003

[54] M. C. Berin, and A. S. Hugh, "Mucosal Immunology of Food Allergy," Current Biology, vol. 23, no. 9, pp. R389-R400, 2013.

[55] J. Pier, E. G. Liu, S. Eisenbarth, and K. M. Järvinen, "The Role of Immunoglobulin A in Oral Tolerance and Food Allergy," Ann Allergy Asthma Immunol, vol. 2021, no. 3, pp. 00090-9, 2021.

[56] B. Bohle, T. Kinaciyan, M. Gerstmayr, A. Radakovics, B. JahnSchmid, and C. Ebner, "Sublingual immunotherapy induces IL-10producing $\mathrm{T}$ regulatory cells, allergen-specific $\mathrm{T}$-cell tolerance, and immune deviation," J Allergy Clin Immunol, vol. 120, no. 3, pp. 70713, Sep, 2007.

[57] O. U. Soyer, M. Akdis, J. Ring, H. Behrendt, R. Crameri, R. Lauener, and C. A. Akdis, "Mechanisms of peripheral tolerance to allergens," Allergy, vol. 68, no. 2, pp. 161-170, 2012.

[58] R. Hinterleitner, and B. Jabri, "A dendritic cell subset designed for oral tolerance," Nat Immunol, vol. 17, no. 5, pp. 474-6, 2016.

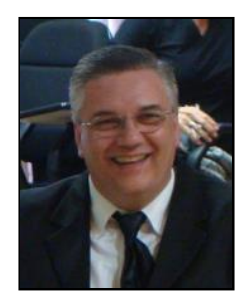

Celso Eduardo Olivier was born in Brazil in 1963. Physician graduated from the Faculty of Medicine of the State University of Campinas (1986). Medical residency at the Faculty of Medicine of the State University of Campinas (1988). Specialist in Allergy and Immunology from the Brazilian Association of Allergy and Immunology (2011). Certified in the area of Pediatric Allergy and Immunology by the Brazilian Society of Pediatrics (2015). Specialist in Clinical Analysis by the Faculty of Health Sciences of the Methodist University of Piracicaba (2012). Doctorate (Ph.D.) in Clinical Medicine (under the guidance of Prof. Dr. Ricardo de Lima Zollner) concluded at the Department of Allergy and Immunology of the Faculty of Medicine of the State University of Campinas (2012).

$\mathrm{He}$ is the Senior Researcher of the Americana's Alergoimuno Institute (Instituto Alergoimuno de Americana). He has experience in the field of Medicine, with an emphasis on Allergy and Immunology and Clinical Analysis, acting mainly on the following themes: in vivo and in vitro diagnosis of food allergy, respiratory allergy, dermatological allergy, skin-allergic tests, leukocyte adherence inhibition tests, precipitins, and immunoblot.

Dr. Olivier is a member of the Brazilian Association of Allergy and Immunopathology. His curriculum vitae can be accessed at: http://lattes.cnpq.br/7035870789320492.

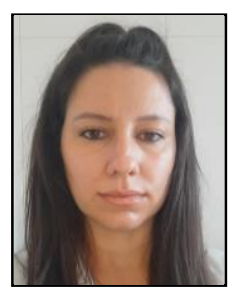

Daiana Guedes Pinto was born in Brazil in 1985. Biomedic graduated from the Faculty of Americana (2010).

She is a researcher in the Americana's Alergoimuno Institute (Instituto Alergoimuno de Americana). $\mathrm{He}$ has experience in the field of laboratory Medicine, acting mainly on the following themes: preparation of allergens and allergoids for allergen immunotherapy, and for in vivo, ex vivo, and in vitro diagnosis of allergy, leukocyte adherence inhibition tests, precipitins, and immunoblot. Her curriculum vitae can be accessed: at http://lattes.cnpq.br/6423437970305610.

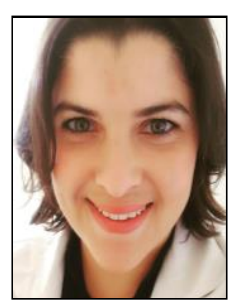

Regiane Patussi dos Santos Lima was born in Brazil in 1985. Biomedic graduated from the Anhanguera Santa Barbara Faculty (2015).

She is a researcher in the Americana's Alergoimuno Institute (Instituto Alergoimuno de Americana). He has experience in the field of laboratory Medicine, acting mainly on the following themes: preparation of allergens and allergoids for allergen immunotherapy, and for in vivo, ex vivo, and in vitro diagnosis of allergy, skin-allergic tests, leukocyte adherence inhibition tests, precipitins, and immunoblot. Her curriculum vitae can be accessed at: http://lattes.cnpq.br/2757001223214460.

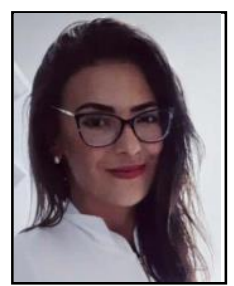

Mariana Dias da Silva was born in Brazil in 1985 Pharmacist graduated from the Faculty of Health Sciences of the Methodist University of Piracicaba (2011).

Former researcher (2012-2021) in the Americana's Alergoimuno Institute (Instituto Alergoimuno de Americana). He has experience in the field of laboratory Medicine, acting on the following themes: preparation of allergens and allergoids for allergen immunotherapy, and for in vivo, ex vivo, and in vitro diagnosis of allergy, skin-allergic tests, leukocyte adherence inhibition tests, and precipitins.

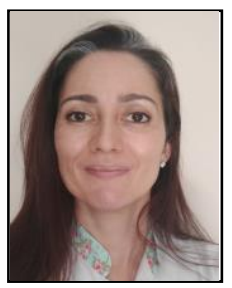

Raquel Acácia Pereira Gonçalves dos Santos was born in Brazil in 1976. Nurse graduated from the Anhanguera Santa Barbara Faculty (2016).

She is a researcher in the Americana's Alergoimuno Institute (Instituto Alergoimuno de Americana). He has experience in the field of diagnostic Medicine, acting mainly on in vivo diagnosis of allergy,

Her curriculum vitae can be accessed at http://lattes.cnpq.br/2757001223214460.

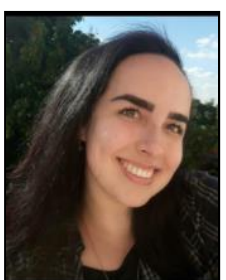

Ana Paula Monezzi Teixeira was born in Brazil Biomedic graduated from the Faculty of Americana (2018).

Former trainee (2018) from the Americana's Alergoimuno Institute (Instituto Alergoimuno de Americana). He was trained in the field of laboratory Medicine, acting mainly on the following themes: preparation of allergens and allergoids for in vivo, ex vivo and in vitro diagnosis of allergy, skin-allergic tests, leukocyte adherence inhibition tests, precipitins and immunoblot. Her curriculum vitae can be accessed at: http://lattes.cnpq.br/9364659098398568.

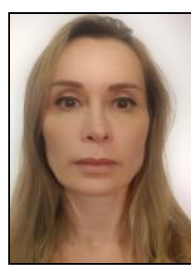

Patricia Ucelli Simioni has Bachelor's degree in Biological Sciences from the State University of Campinas-UNICAMP (1994), master's degree in Biology-Immunology (1998), Ph.D. in Genetics and Molecular Biology (2004) and Ph.D. in Immunology (2008) Bioagents of UNICAMP. Teaching professor, accredited with the post-graduation program in Cellular and Molecular Biology of UNESP (2014).

She has teaching experience in Biochemistry, Immunology and General Biology, acting in the areas of Immunology, Gastroenterology and Biochemistry, with emphasis on: immunoregulation, aging, autoimmune diseases, colitis, Crohn's disease, dendritic cells, aging and monoclonal antibodies.

Dr. Ucelli is a full professor, scientific reviewer, trainee supervisor, CBT counselor, member of the Structuring Teaching Nucleus (NED) and the Permanent Evaluation Committee (CPA) of Americana-FAM College, Americana-SP. She also coordinates students of scientific initiation and masters. Her curriculum vitae can be accessed at http://lattes.cnpq.br/9031391911633603. 